\title{
Minimally Invasive Endoscopic and Endoscopy-Assisted Microsurgery of Vestibular Schwannoma
}

\author{
Betka Jan et al." \\ Charles University in Prague, $1^{\text {st }}$ Faculty of Medicine, \\ Department of Otorhinolaryngology and Head and \\ Neck Surgery, Faculty Hospital Motol, Prague, \\ Czech Republic
}

\section{Introduction}

Endoscopic techniques have revolutionized the practice of surgery in a number of specialities. Endoscopes have the ability to provide high magnification and illumination of the operative field, as well as the possibility to look around the corner past obstructing tissues and structures, thus allowing for more radical and safer surgeries. With several clinical applications, smaller incisions and surgical approaches are now possible, resulting in decreased postoperative pain, faster rehabilitation, better cosmetic results, and shorter hospitalization.

Similar to other specialities the endoscope represents an established component of the contemporary skull base surgery armamentarium. Its application in various skull base, otologic and neurosurgical procedures, either as a sole visualizing tool or as an adjunct to the microscope, is constantly expanding. The aim of this chapter is to review the application of endoscopic techniques in the treatment of vestibular schw annoma.

\section{Vestibular schwannoma}

Vestibular schwannomas are benign, slow-growing tumors which arise from the sheath of the eighth cranial nerve. The transition zone (Obersteiner-Redlich zone) of the superior or inferior vestibular nerves where the covering myelin changes from a central to a peripheral type or vestibular ganglion are estimated to be the site of pathologic proliferation of Schwann cells leading to tumor (Tallan et al. 1993, Zverina, 2010). Thus acoustic neuroma or

\footnotetext{
${ }^{*}$ Chovanec Martin ${ }^{1,2}$, Zverina Eduard ${ }^{1,3}$, Profant Oliver ${ }^{1,4}$, Lukes Petr ${ }^{1}$, Skrivan Jiri ${ }^{1}$, Kluh $\mathrm{Jan}^{1}$ and Fik Zdenek ${ }^{1,2}$

${ }^{1}$ Charles University in Prague, $1{ }^{\text {st }}$ Faculty of Medicine, Department of Otorhinolaryngology and Head and Neck Surgery, Faculty Hospital Motol, Prague, Czech Republic

${ }^{2}$ Charles University in Prague, $1^{\text {st }}$ Faculty of Medicine, Institute of Anatomy, Prague, Czech Republic

${ }^{3}$ Charles University in Prague, $3^{\text {rd }}$ Faculty of Medicine, Department of Neurosurgery, Faculty Hospital Kralovske Vinohrady, Prague, Czech Republic

${ }^{4}$ Department of Auditory Neurosciene, Institute of Experimental Medicine AS CR, Prague, Czech Republic
} 
neurinoma represent misnomers. The proportion of tumors arising from each of the two vestibular nerves superior or inferior has been reported to be equal (Clemis et al. 1986). There are two distinct clinical presentations for vestibular schw annomas: Sporadic unilateral tumor is the most common form occurring in $95 \%$ of cases, and the rare hereditary bilateral tumors which are typically a sign of neurofibromatosis type 2 .

Vestibular schwannomas have an incidence of 10 to 15 per million per year and represent the most common tumor in neurotology (Myrseth et al. 2007, Zverina, 2010). These tumors account for approximately $10 \%$ of all intracranial and 80 to $95 \%$ of cerebellopontine angle tumors (Springborg et al. 2008). Most commonly vestibular schw annomas occur during the fourth and fifth decades of life and with slightly higher incidence among females than males. The reported increasing incidence along with the higher prevalence of smaller tumors being diagnosed during the last decades probably reflect improvements in diagnostic methods and growing awareness of both patients and specialists rather than a true increase in tumor incidence (Stangerup et al. 2010).

The diagnosis is either made or suspected based on clinical symptoms at presentation, audiometric testing, or imaging methods. Symptoms and signs associated with vestibular schwannomas have been known for over 150 years and are due to direct tumor compression, invasion or vascular compromise of the surrounding structures (Betka et al. 2008).

Hearing loss is the most common and also most frequent initial symptom and reason for patients to seek medical care. Typically, patients will develop a slowly (over months or years) progressive hearing loss. Despite not being specific, progressive sensorineural hearing loss at the high frequencies is the most common finding. Sudden onset of hearing loss is found in 12-22\% of patients (Myrseth et al. 2007). Normal hearing is reported in about $5 \%$ of patients. Tinnitus is the second most frequent symptom of vestibular schwannoma. Its incidence usually coincides with hearing loss. Tinnitus may be constant or fluctuating in quality and quantity. Rarely is tinnitus the only symptom. Hearing loss indicates either damage of the cochlear nerve or occlusion of the labyrinthine artery. The origin of tinnitus is uncertain as it can be present even in the deaf ear. In conclusion, any unilateral or asymmetric sensorineural hearing loss and unilateral tinnitus deserve attention (Betka et al. 2008).

Vestibular symptoms are found in $40-60 \%$ of patients who may report a combination of vertigo, dizziness and unsteadiness. Balance problems are minor in the majority of patients probably reflecting very slow destruction of the vestibular nerve during the tumor growth however, once the tumor becomes expansive symptoms tend to worsen. Dysequilibrium is the most common vestibular symptom. Initially it is due to reduced or abolished unilateral peripheral vestibular function and incomplete compensation due to the tumor. It tends to be constant in nature, progressive in severity and aggravated by head movements. True vertigo, occurring in about 5-10\% of cases, typically occurs early in the history of the tumor growth and may last for several days and weeks before resolving due to compensation of the acute peripheral vestibular function loss (Betka et al. 2008). Persistent vertigo is associated with a significant reduction in quality of life among vestibular schwannoma patients (Myrseth et al. 2007, Saman et al. 2009). In patients with large tumors, dysmetria and ataxia due to cerebellar and brainstem compression are common signs.

Headache is recalled by $10-30 \%$ of patients. It is typically described as a fullness or pressure in the ear or retroauricular region ipsilateral to the tumor. Trigeminal nerve compression 
and stretching may manifest as a paresthesia, hypesthesia or neuralgia occurring in about 5$10 \%$ of cases. Clinically apparent facial nerve dysfunction is a relatively rare finding as facial nerve tolerates a large degree of compression, stretching and distortion (Betka et al. 2008).

The grow th rate of vestibular schwannoma varies and can be categorized into one of three patterns: slow (1-2 $\mathrm{mm} /$ year), medium $(2-4 \mathrm{~mm} /$ year), and fast $(1-2 \mathrm{~cm} / \mathrm{year})$. The majority of tumors grow slowly and in some cases spontaneous regression was reported (Zverina et al. 2010).

If not treated, vestibular schwannomas can reach a remarkable size causing severe compression of the brainstem and cerebellum eventually leading to hydrocephalus and intracranial hypertension (Zverina, 2010). However, many of these tumors fail to become symptomatic during a patient's life (Betka et al. 2008).

There are three treatment options for patients with a vestibular schwannoma: observation, radiosurgery/ radiotherapy, and microsurgery.

The concept of observation (wait and scan) is based on two main principles. First, a high proportion of vestibular schwannomas do not grow or grow very slowly following the diagnosis. Second, there is little evidence that active treatment of a non-growing lesion is beneficial to the patient, but it is well documented that active treatment may cause additional complaints and decrease quality of life (Martin et al. 2001, Myrseth et al. 2006, Cheng et al. 2009, Myrseth et al. 2009). Therefore, in spite of increasing hearing loss in many patients, the conservative approach may be a reasonable option for patients with small and medium sized tumours (Yamakami et al. 2003, Sandooram et al. 2004, Zverina, 2010, Sughrue et al. 2011). For the success of observation close follow up and patient's compliance are crucial. The failure rate (e.g. continuous growth or new and progressive symptoms) that need conversion to active treatment is reported to be 15-50\% (Wackym, 2005, Myrseth et al. 2007, Betka et al. 2008).

Although there are enthusiastic supporters for both arms of active treatment (e.g. radiosurgery/ radiotherapy and microsurgery), the data on which to base an objective opinion are incomplete (Yamakami et al. 2003, Myrseth et al., 2007, Myrseth et al. 2009, Zverina, 2010). Radiosurgery refers to the delivery of a therapeutic radiation dose in a single fraction while radiotherapy represents the delivery of a therapeutic radiation in multiple fractions. Radiosurgery represented by the Leksell's gamma knife surgery (GKS) represents the treatment strategy with the biological chance of achieving permanent tumor control for late-responding and slowly proliferating tumors as vestibular schwannoma (Linskey, 2000). Other methods of stereotactic radiosurgery such as linear accelerator (LINAC) and cyber knife, and fractionated radiotherapy are employed for treatment of vestibular schwannomas with similar results (Wackym, 2005, Sakamoto et al. 2009). Radiosurgery does not attempt to eliminate the tumor or cure patients thus it is difficult to compare with microsurgery. Ideal results of radiosurgery are control/ no further grow th of tumor, preservation of facial nerve function and hearing without any complications. This form of treatment is not appropriate for patients with tumors larger than $3 \mathrm{~cm}$ in diameter, as radiosurgery is problematic in larger tumors. Indications in patients with intrameatal tumors, tumors indenting the brainstem and patients with balance problems is also speculative (Wackym, 2005, Zverina, 2010, Cakrt et al. 2010).

The majority of centers report tumor control rates between 90 and $100 \%$, but few report observation periods longer than five years (Myrseth et al. 2007). Useful hearing preservation is reported in about half of cases approaching 3-4 years after radiosurgical treatment (Yang 
et al., 2010). The effect on tinnitus and vertigo is largely unknown (Wackym et al. 2008, Gerosa et al. 2010). Post-irradiation facial and trigeminal nerve dysfunction decreased to less than 5\% as the treatment dose to the tumor margin has been gradually lowered during the last decades thus making the treatment very attractive for the patients and physicians (Myrseth et al. 2007, Myrseth et al. 2009). Hydrocephalus after stereoradiosurgical treatment is reported in 2-4\% of patients. The mechanism of its development remains controversial. Frequent monitoring and early intervention is highly recommended to prevent irreversible cerebral damage (Myrseth et al. 2007). Induction of secondary neoplasia and malignant transformation of vestibular schwannoma has been reported rarely (Zverina, 2010).

Despite the fact that published data are difficult to interpret, mainly due to lack of long-term follow up, changing treatment protocols, lack of control groups, limited understanding of the natural history of treated tumors, insufficient stratification of patients and incomplete reporting results, there is little debate that radiosurgery has the ability to achieve tumor control with short-term low complication rates and a shorter hospital stay, and its role in the treatment of vestibular schwannoma is expanding (Wackym, 2005, Myrseth et al. 2007).

The objectives of surgical management are radical resection of the tumor, preservation of facial nerve function, conservation of hearing, and preservation of neighbouring neurovascular structures. Surgical treatment is technically challenging with gradual learning curve (Roser \& Tatagiba, 2010). In many contemporary centres, vestibular schwannoma patients are operated on by a multidisciplinary team consisting of neurootologist and neurosurgeon. Ideally, it is a true team with each participant capable of performing the entire operation (Skrivan et al. 2004, Myrseth et al. 2007). This unique cooperation among the two disciplines has allowed each to bring the best of their speciality to the management of vestibular schw annoma (Zverina et al. 2010).

Three different approaches (e.g. translabyrinthine, middle fossa and retrosigmoid) were developed for the microsurgical treatment of vestibular schwannoma. Debate continues as to which of the three approaches is best suited for large and for small tumors, and which technique allows for best results. Several articles have eloquently outlined the advantages and disadvantages of each approach (Colleti \& Fiorino, 2005, Wackym, 2005, Myrseth et al. 2007, Betka et al. 2008, Sughrue et al. 2010a, Sughrue et al. 2010b). The translabyrinthine and the retrosigmoid approaches can be used for all tumor sizes, whereas the middle fossa approach is useful only for removal of intrameatal tumors. Hearing preservation can be achieved only through the retrosigmoid and middle fossa approaches. The approach is chosen based on criteria such as tumor size, internal auditory canal extension, preoperative hearing level, and the surgeon's experience. Many teams employ all three approaches in an effort to take advantage of each of them and to achieve the best outcome for each patient. Radical tumor removal can be achieved in the majority of cases, and there is a seldom role for partial resection (e.g. preservation of functional neural structures, advanced patient age, hearing status in the contralateral ear).

The morbidity associated with vestibular schwannoma surgery has declined steadily since the first successful operation was performed more than 100 years ago. The development of the surgical microscope in the 1960s revolutionized the field of its treatment.

Recent results following microsurgical removal of vestibular schwannomas are in general excellent although mortality and morbidity are not completely eliminated. Today most large series report mortality rates of $1 \%$ or less (Yamakami et al. 2003, Myrseth et al. 2007, Zverina et al. 2010). Facial nerve injury, hearing loss, postoperative balance problems, cerebrospinal fluid leak and headache are among the main risks of surgical treatment of vestibular schwannoma. 
With the routine use of intraoperative neuromonitoring anatomic preservation of facial nerve in the large series from the centers ranges from 90\% to 100\% (Wackym, 2005, Myrseth et al. 2007). Even if facial nerve is anatomically and physiologically intact after tumor resection, paresis may develop during the early postoperative period with improvement of function gradually over the next months. The single most important predictive factor of facial nerve preservation is the size of the treated tumor. In the group of surgically treated small and medium size tumors normal function of the facial nerve can be achieved in the vast majority of cases. Immediate postoperative normal function was shown to be better in cases of retrosigmoid and translabyrinthine approaches (Colleti \& Fiorino, 2005). In the group of large tumors immediate postoperative normal facial nerve function can be achieved in about $50 \%$ of cases treated by the experienced team with subsequent improvement to normal or near normal (House Brackmann grade I and II) in about 60 to $80 \%$ of cases (Magnan et al. 2002, Zverina, 2010). Tumor adherence to the facial nerve, intraoperative monitoring and age represent also important prognostic markers of facial nerve preservation (Sughrue et al. 2010b).

Type of surgical approach, tumor size, younger age of the patient, and the use of intraoperative monitoring have all been implicated as predictive factors of hearing preservation. Beside surgical experience and skill, the chance for hearing preservation is influenced by the proper identification of the cochlear nerve and tumor adhesion to the cochlear nerve. Hearing preservation in patients with large tumors is difficult and less likely to succeed compared with small or medium-sized tumors. Reported hearing preservation in the case of tumors $>2 \mathrm{~cm}$ ranges from 5 to $53 \%$ (Wanibuchi et al. 2009). The success rate in the group of small tumors is significantly better ranging from 17 to $100 \%$ in some series. In a recent review of results of hearing preservation after microsurgical resection the hearing preservation rate was $64 \%$ in tumors $<1 \mathrm{~cm}$ and $61 \%$ in tumors $1-1.5 \mathrm{~cm}$. The results of this multivariate analysis have shown the middle fossa approach to be more effective for preservation of hearing. The increased risk of surgically related hearing loss with retrosigmoid approach possibly reflect the fact that in this approach the cochlear nerve usually presents on the microscopically blind anterior side of tumor, and is encountered late, while the middle fossa approach permits earlier identification of the nerve, which can subsequently be safely avoided during tumor resection (Sughrue et al. 2011).

Following surgery, patients may develop balance problems, but eventually most recover well. Vestibular compensation after tumor removal and vestibular nerve sectioning can take weeks to months. Large tumor size, postoperative rehabilitation, central vestibular pathology and cerebellar dysfunction, surgical approach, impairment of vision a depression are among the main factors that influence the eventual level of compensation and the time taken to achieve this (Saman et al. 2009, Cakrt et al. 2010).

Some pain is expected in most patients immediately after surgery. Headache that persists weeks to months after surgery is not a major problem in the majority of patients but in some cases it can be incapacitating and decreasing quality of life. The reported incidence of postoperative headache has ranged from $0 \%$ to $73 \%$ depending on the type of surgical approach, technique used, and interval since surgery. The retrosigmoid approach was associated with higher incidence of debilitating persistent postoperative headache when compared with the translabyrinthine or middle fossa approaches. There is evidence indicating that a standard craniectomy may be associated with significant postoperative headache, which may be reduced with minimal bone removal during craniectomy (Magnan et al. 2002, Ryzenman et al. 2005, Wackym et al. 2005, Myrseth et al. 2007). 
Recurrence rates after radical tumor removal, regardless of the type of approach used is less than $2 \%$. There are compelling reasons to conclude that the recurrence rate is higher if hearing preservation approaches are employed reflecting possibly incomplete tumor removal, especially at the fundus of the internal auditory canal (Yamakami et al., 2003, Zverina, 2010).

Cerebrospinal fluid leak is the most common postoperative complication with the rate of around 10 to $20 \%$ of patients. It is associated with a higher risk of meningitis and must therefore be recognized and treated promptly. According to some works leakage after retrosigmoid or middle fossa approaches are more likely to require surgical intervention than a leak after a translabyrinthine approach. The majority of leaks are a result of poor intraoperative identification of exposed air cells within the temporal bone (Wackym et al. 1999, Zverina, 2010)

\section{Historical perspective of endoscopic surgery of the cerebellopontine angle}

Development of endoscopic surgery of vestibular schwannoma parallels application of endoscopes for other procedures in the cerebellopontine angle (e.g. diagnostic cisternoscopy, vestibular neurectomy, microvascular decompression) thus it must be understood in its broader context.

Urologist L'Espinase through use of a cystoscope attempted fulguration of the choroid plexus bilaterally in two infants with hydrocephalus in 1910 (Ozluoglu \& Akbasak, 1996, as cited in Davis 1936). Doyen, who reported an endoscopic approach to the fifth cranial nerve by means of a retrosigmoid craniectomy in 1917, is credited with being the first to use an endoscope for the cerebellopontine angle surgery. He also developed instruments for the endoscopic division of the sensory roots of the nerve (Doyen, 1917).

In the late 1940s and early 1950s, the development of a coherent fiber optic bundles for image transmission, and an incoherent bundle for light transmission by Hopkins greatly aided the improvement of endoscopes that are used in modern surgical practice (Prott, 1974, Griffith, 1975, Mer et al. 1967). Later on the endoscopic anatomy of the cerebellopontine angle via translabyrinthine end retrosigmoid approach was described in detail by Prott and Opel (Prott, 1974, Opel, 1974, 1981, O`Donough et al. 1993).

Bremond and co-workers were the first reported minimally invasive retrosigmoid approach to treat the cerebellopontine angle pathologies. The authors had established that the procedure requires only a small retroauricular incison and craniectomy and the risk of the this appears to be minimal (Bremond et al. 1974, Bremond et al. 1975). Similary Fukushima used the endoscope to explore the cerebellopontine angle, cisterna magna, C1-C2 space and Meckel's cave from small burr hole and stated that cisternoscopy could be useful for the differential diagnosis of small tumors, vascular abnormalities or neurovascular compression syndromes (Fukushima, 1978).

In the 1990s few teams supported the employment of endoscopy during the retrosigmoid or retrosigmoid-retrolabyrinthine microsurgery of vestibular schwannoma. Endoscope was shown to be an ideal adjunct to hearing-preserving microsurgery of vestibular schwannomas, enabling direct control of the lateral aspects of the internal auditory canal, intrameatal portion of tumor and nerves while decreasing the rate of potential complications (Magnan et al. 1993, McKennan 1993, Magnan et al. 1994, Rosenberg et al. 1994, Tatagiba et al. 1996, Goksu et al. 1999, King \& Wackym, 1999, Wackym et al. 1999). Benefits of the endoscope during microsurgical vestibular neurectomy to treat intractable vertigo (e.g. 
Meniere's disease) were described at the same time. It was shown that endoscopy allows improved identification of the nervus intermedius, facial, cochlear, and vestibular nerves and adjacent neurovascular relationships without the need for significant brain retraction. In addition, endoscope was shown to be beneficiary for identification of the cleavage plane between the cochlear and vestibular nerves.

Endoscopy was also evaluated for the placement of an auditory brainstem implant via the translabyrinthine, retrosigmoid, and middle cranial fossa approaches. Authors stated that endoscopy provided superior visualization of the lateral recess of the fourth ventricle than the operating microscope with all approaches and recommended the retrosigmoid approach as it provides the best view of the implantation site and the easiest angle for placement of the neuroprosthesis (Friedland \& Wackym, 1999).

Endoscopic technique and assistance during microvascular decompression of the facial nerve for hemifacial spasm, trigeminal nerve for trigeminal neuralgia, glossopharyngeal nerve for glossopharyngeal neuralgia, and cochlear nerve for incapacitating tinnitus were shown to add additional accuracy rate in identifying nerve-vessel conflicts and even revealed a significant number of persistent nerve compression in despite negative binocular microscopic evidence (Magnan et al. 1993, Magnan et al. 1997, Jarrahy et al. 2000, Badr-El-Dine et al. 2002, El-Garem et al. 2002, Miyazaki et al. 2005, Chen et al. 2008, Guevarra et al. 2008).

Growing experience with endoscopic control and assistance for microsurgical management of other cerebellopontine angle pathologies led to a broader application of these techniques for tumor treatment including vestibular schwannomas, meningiomas and epidermoids (Magnan et al. 1993, King \& Wackym, 1999, Wackym et al. 1999, Magnan et al. 2002, Schroeder et al. 2004, Hori et al. 2006, de Vitiis et al. 2007). Progressive implementation of rigid endoscopy in cerebellopontine angle surgery, has revealed it to be an equal if not superior imaging tool in this anatomic region. Cerebellopontine angle endoscopy was no longer seen as a risky procedure (Ozluoglu \& Akbasak, 1996, Fries \& Pernecki, 1998, Pernecki \& Fries, 1998, Wackym et al. 1998, Miyazaki et al. 2005, Koval, 2009). Although its use has been described as an adjunctive imaging modality in many surgical procedures the use of endoscopy as the sole means of intra-operative imaging in this setting has not been reported at that time.

Microvascular decompressions were the first fully endoscopic procedures reported (Eby et al. 2001, Jarrahy et al. 2002a, Jarrahy et al. 2002b, Kabil et al. 2005, Cheng et al. 2008). The first report of fully endoscopic resection of vestibular schwannoma was by Shainian and coworkers in 2004 (Shahinian et al. 2004). Kabil and Shahinian in 2006 have presented 112 fully endoscopic procedures performed via $1.5 \mathrm{~cm}$ retrosigmoid craniotomy with excellent results. 95\% tumors were completely removed. Subtotal removal was performed in $5 \%$ of patients in an attempt to preserve their hearing. Anatomical preservation of the facial nerve was achieved in all patients and of the cochlear nerve in $82 \%$ of hearing ears. Some or serviceable hearing was preserved in $58 \%$ of preoperative cases. There were no major neurological complications (Kabil \& Shahinian, 2006).

Recently, the first high-definition (HD) cameras designed for endoscopic surgery have been developed. They provide the HD Television (HDTV) image format that provides an image with improved color fidelity and enhanced image resolution that is comparable to the image obtained when looking through the microscope. Their application in the cerebellopontine angle surgery is promising. Comparing the standard three-chip camera with a HD three- 
chip camera for video-assisted vestibular schwannoma surgery and microvascular decompression has provided a more detailed image with improved resolution of tissue and vasculature of the tumor, nerves and brainstem (Schroeder and Nehlsen, 2010).

\section{Rationale for endoscopic surgery of the vestibular schwannoma}

The main goals in vestibular schwannoma surgery are complete tumor removal with preservation of neurovascular structures and their function (e.g. facial nerve, hearing), and minimization of the sequelae of surgery and its complications (e.g. persistent balance problems, headache, cerebrospinal fluid leaks). The development of the surgical microscope in the 1960s revolutionized the field of both otology and neurosurgery as it provided accurate and detailed imaging of very restricted spaces, with simultaneous possibility of bimanual dissection. Despite the fact that endoscopic technique is applicable for each type of vestibular schwannoma surgical approach its benefits were predominantly shown to overcome some of the main disadvantages of the microsurgical retrosigmoid approach (Low 1999a).

Compared with the surgical microscope, endoscopes provide a wide angle of view with superb illumination in the depth and an increased depth of focus even with high magnification. Employment of endoscopic technique allows unobstructed visualization of all critical neurovascular structures of the cerebellopontine angle with simultaneous reduction in the craniotomy size, thus eliminating or at least reducing the need for retraction of the cerebellum. Both factors might reduce the number of complications resulting from dissection in this region (Magnan et al. 2002, Goksu et al. 2006).

Furthermore, angled optics expand the lateral boundaries of the microsurgical view. Endoscopes with angles of $30^{\circ}, 45^{\circ}$ and $70^{\circ}$ can be used for early identification of the relationship between the tumor and neighboring structures in the cisternal part of dissection. The early identification of the brainstem and neurovascular structures (e.g. early identification of the position of the facial nerve to tumor or inspection of relationship between the tumor and brain or vessels) in the case of large tumors may be important in order to plan subsequent surgical steps (Fries \& Pernecki 1998, Gerganov et al. 2009).

Using the surgical microscope with its direct forward view, it is virtually impossible to look around the corner due to the oblique angle of the internal auditory canal in relation to the trajectory of the dissection. Inability to completely visualize the lateral extent of the tumor as well as incomplete visualization of the exposed air cells are among the main disadvantages of the retrosigmoid approach. Excessive drilling of the petrous bone that is necessary in tumors extending to the lateral parts and fundus of internal auditory canal needed to achieve safe and radical tumor removal, might hamper the chance for hearing preservation as a consequence of injury of the posterior semicircular canal or labyrinth (Koval et al. 1993, Low 1999b, Goksu et al. 2005). Simultaneously, extensive drilling of the posterior meatal wall with improper sealing of the opened pneumatic system is associated with increased risk of cerebrospinal fluid leak (Valtonen et al. 1997). All these disadvantages can be alleviated by angled endoscopes that can be used for both inspection and visualization of the tumor and neurovascular structures during dissection within the internal auditory canal. Moreover, after completion of tumor removal the endoscope can be used to inspect the fundus for residual tumor and integrity of labyrinthine artery, facial and cochlear nerve. Similarly endoscopes are used for visualization of the drilled-out portion of the petrous bone for opened air cells that might need sealing. Some authors report that the risk of 
cerebrospinal fluid leaks have been lowered or even completely avoided (Valtonen et al. 1997, Wackym et al. 1999, Wackym et al. 2002, Gerganov et al. 2010). Under specific anatomical conditions angled endoscopes can be beneficial to identify and manage high jugular bulb (Betka et al. 2010). Minimally-invasive approach with limited bony removal is advantageous for the case of eventual Bone Anchored Hearing Aid implantation in case of single sided deafness rehabilitation.

Endoscopic approach for vestibular schwannoma surgery has some potential disadvantages as well. The two-dimensional view obtained by the endoscope instead of the threedimensional view of the microscope represents an often cited disadvantage. Compared to the static imaging obtained by the surgical microscope, endoscopes of varying diameter, length and angulation allow surgeons to dynamically rotate and alter their perspective of the surgical field to compensate for the two-dimensional view. This amounts to a greater appreciation of the three-dimensional relationships between the tumor and the surrounding structures (Kabil \& Shahinian, 2006). Furthermore novel binocular three-dimensional endoscopical technique during skull base surgery facilitating depth perception has been described recently.

Because angled endoscopes have a sharp front edge compared with a $0^{\circ}$ endoscope, the surgeon cannot see the insertion trajectory directly. It is necessary to keep in mind that there could be a risk of damaging the neurovascular structures (Hori et al., 2006). Cerebellum can be protected during the procedure by covering it with a neurosurgical cotton, piece of Penrose drain or artificial dura. However working with $30^{\circ}$ endoscopes has been repeatedly shown to be safe (Magnan et al. 2002, Goksu et al. 2005, Miyazaki et al. 2005). Risk of injury with insertion of $45^{\circ}$ and $70^{\circ}$ endoscopes is probably higher, but this can best alleviated by microscopic control. Complications due to inadvertent injury of healthy tissues have not been reported reflecting judicious use of the instruments.

As the delicate bimanual dissection is crucial for safe management of neurovascular structures of the cerebellopontine angle, a significant number of experts always struggled against the possibility of compromising one of their hands in endoscopic handling. However this potential problem was solved with introduction of either rigid pneumatic holding arms for the endoscope or freehand endoscopic technique with the endoscope being moved and held by a second surgeon. Both techniques were shown to be safe at allowing bimanual surgical dissection (Eby et al. 2001, Jarrahy et al. 2002a, Jarrahy et al. 2002b, Schroeder et al. 2004, Kabil \& Shahinian, 2006, de Vitiis et al. 2007). Another important step forward was the introduction of an irrigation system, eliminating the time consuming and unsafe practice of removing and reinserting the endoscope.

Among the main drawbacks of endoscopic surgery of vestibular schwannoma is the risk of injury of very sensitive and critical structures of the cerebellopontine angle as the endoscope does not see the instrument used before it passes in front of the lens. Thus it is mandatory to achieve synchronized, in-and-out movements of the endoscope together with the instruments (Jarrahy et al. 2002a, Jarrahy et al. 2002b, Kabil \& Shahinian, 2006, de Vitiis et al. 2007). Using the video-endoscopy assisted microsurgical technique the handling of instruments is controlled by the microscope before coming in front of the lens of the endoscope (Magnan et al. 2002, Miyazaki et al. 2005, Betka et al. 2010, Gerganov et al. 2010).

Another potential risk of the endoscopic technique is possibility of heat injury from prolonged use of the endoscope too close to the cranial nerves and other brain structures (Betka et al. 2010, Gerganov et al. 2010). Thus it is of the utmost importance to irrigate the operating field regularly, because the tip of the endoscope may become very hot (Wackym 
et al. 2002, Magnan et al. 2002, Goksu e al. 2005, Hori et al. 2006, Betka et al. 2010, Gerganov et al. 2010).

\section{Endoscopic anatomy of the cerebellopontine angle}

O'Donoghue and O'Flynn divided the CPA area into four levels on the basis of neuroendoscopic inspection of 10 fresh cadaver heads (O'Donoghue \& O'Flynn, 1993). Level 1 contains the trigeminal and abducens nerves, Meckel's cave, superior cerebellar artery and superior petrosal vein. Level 2 contains the acousticofacial bundle and anterior inferior cerebellar artery. Level 3 contains the lower cranial and posterior inferior cerebellar artery. Level 4 contains the lower medulla, spinal cord, spinal root of the accessory nerve and hypoglossal nerve.

The majority of authors rather divide the region of cerebellopontine angle into three neurovascular complexes with no distinct borders (Rhoton, 2000a, Yuguang et al. 2005). The upper complex is related to the superior cerebellar artery, a middle complex related to the anterior inferior cerebellar artery and a lower complex related to the posterior inferior cerebellar artery (Fig.1). Each neurovascular complex includes one of the three parts of the brainstem (midbrain, pons, medulla), one of the three surfaces of the cerebellum (e.g. tentorial, petrosal and occipital), one of the three cerebellar peduncles, and one of the three major fissures between the cerebellum and the brainstem. In addition, each neurovascular complex contains a group of cranial nerves.
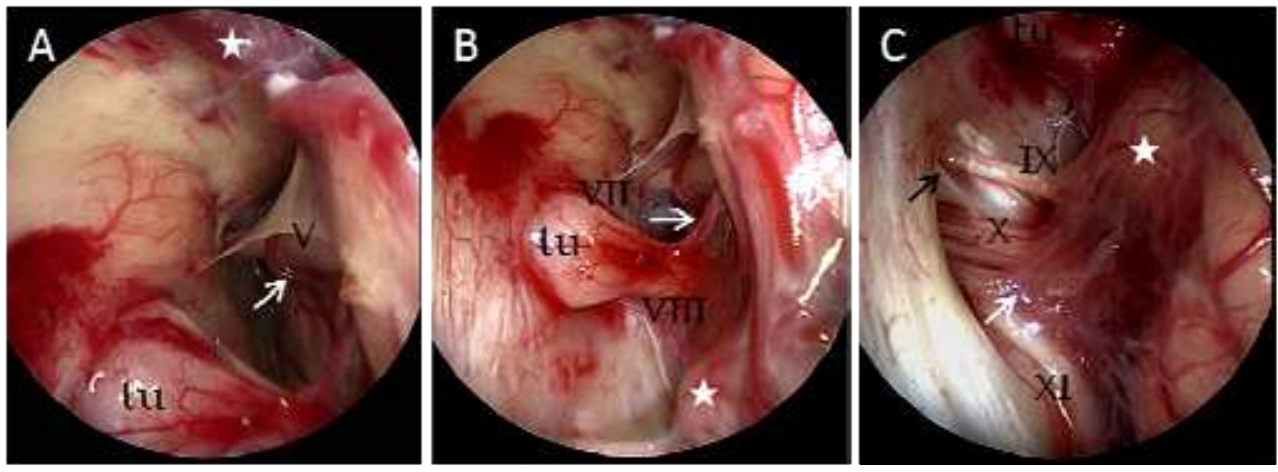

Fig. 1. Endoscopic anatomy of the cerebellopontine angle (left side). A: Upper neurovascular complex with the superior cerebellar atery (arrow) over the trigeminal nerve (V) and superior petrosal vein (asterisk); B: Middle neurovascular complex with the anterior inferior cerebellar atery (arrow), bundle of the facial (VII) and vestibulocochlear (VIII) nerves is distorted by the tumor (tu), floculus (asterisk); C: Lower neurovascular complex with the posterior inferior cerebellar atery (white arrow) over the lower cranial nerves. The spinal accessory fibers (IX) enter the jugular foramen bellow the cranial fibers of the eleventh cranial nerve that is in contact with the vagus nerve (X). Glossopharyngeal nerve at the level of the jugular foramen enters the glossopharyngeal meatus, that is separated by a dural septum (black arrow) from the vagal meatus.

The upper neurovascular complex includes the superior cerebellar artery, midbrain, cerebellomesencephalic fissure, superior cerebellar peduncle, tentorial surface of the 
cerebellum, and the oculomotor, trochlear, and trigeminal nerves (Fig.1) (Rhoton, 2000a, Cappabianca et al. 2002, Yuguang et al. 2005).

The superior cerebellar artery (SCA) arises in front of the midbrain, usually from the basilar artery near its apex. The artery passes below the oculomotor nerve, but may infrequently arise from the proximal posterior cerebral artery and pass above the oculomotor nerve. Close to its origin superior cerebellar artery encircles the brainstem near the pontomesencephalic junction, passing below the trochlear nerve and above the trigeminal nerve. Its proximal portion courses medial to the free edge of the tentorium cerebelli, and its distal part passes below the tentorium. After passing above the trigeminal nerve, it reaches the cerebellomesencephalic fissure, where it runs on the superior cerebellar peduncle and terminates by supplying the tentorial surface of the cerebellum (Rhoton, 2000a, Rhoton 2000b, Rhoton, 2000c).

The trigeminal nerve joins the brainstem about halfway between the lower and upper borders of the pons. Junction of the sensory rootlets of the nerve (e.g. main cone) with the brainstem is frequently obscured by little projection of cerebellum. There may be aberrant sensory rootlets that penetrate the pons outside the main sensory cone. These are typically rostral to the main cone and related to the first division of the nerve. Motor rootlets arise even more rostral to the main sensory cone. The trigeminal nerve runs obliquely upward from the lateral part of the pons tow ard the petrous apex. Fibres of the third-division remain caudolateral while the fibres of the first-division remain rostromedial during the course from the pons to the trigeminal ganglion. The fifth nerve exits the posterior fossa to enter the middle cranial fossa by passing forward and beneath the tentorial attachment to enter Meckel's cave, which sits in the trigeminal impression on the upper surface of the petrous part of the temporal bone (Rhoton, 2000a).

The superior petrosal vein (SPV) is one of the most frequently encountered veins during vestibular schwannoma surgery. SPV may be formed by the terminal segment of a single vein or by the common stem formed by the union of several veins that empty into the superior petrosal sinus. Tributaries of the SPV are the transverse pontine and pontotrigeminal veins, the veins of the cerebellopontine fissure and the middle cerebellar peduncle, and the common stem of the veins draining the lateral part of the cerebellar hemisphere (Rhoton, 2000a, Rhoton 2000d, Ebner et al. 2009, Koerbel et al. 2009).

Understanding the anatomy of the middle neurovascular complex is crucial for the surgical treatment of vestibular schwannoma (Fig.1) (Rhoton, 2000a, Magnan et al. 2002, Miyazaki et al. 2005). The middle complex includes the anterior inferior cerebellar artery, pons, middle cerebellar peduncle, cerebellopontine fissure, petrosal surface of the cerebellum, and the abducens, facial, and vestibulocochlear nerves (Rhoton, 2000a, Cappabianca et al. 2002, Yuguang et al. 2005).

The anterior inferior cerebellar artery (AICA) arises at the pontine level from the basilar artery, usually as a single trunk. Its origin can be bifurcated or even triplicated. From its origin AICA courses backward around the pons being in contact with the abducens nerve, and proceeds to the cerebellopontine angle where it is related to the facial and vestibulocochlear nerves. After coursing near and sending branches to the facial and vestibulocochlear nerves entering the internal auditory canal and to the choroid plexus protruding from the foramen of Luschka, it passes around the flocculus on the middle cerebellar peduncle to supply the lips of the cerebellopontine fissure and the petrosal surface of the cerebellum. AICA commonly bifurcates near the seventh-eighth nerve 
complex to form a rostral and a caudal trunk. The rostral trunk sends its branches laterally along the middle cerebellar peduncle to the superior lip of the cerebellopontine fissure and the adjoining part of the petrosal surface, and the caudal trunk supplies the inferior part of the petrosal surface, including a part of the flocculus and the choroid plexus. The AICA gives rise to perforating arteries to the brainstem, choroidal branches to the tela and choroid plexus, and the nerve-related arteries, including the labyrinthine, recurrent perforating, and subarcuate arteries (Rhoton, 2000a, Rhoton 2000b).

The facial nerve arises from the brainstem near the lateral end of the pontomedullary sulcus 1 to $2 \mathrm{~mm}$ anterior to the point at which the vestibulocochlear nerve joins the brainstem at the lateral end of the sulcus. The interval between the seventh and eighth nerves is greatest at the level of the pontomedullary sulcus and decreases as these nerves approach the porus of internal auditory canal.

Glossopharyngeal nerve, foramen of Luschka and flocculus can be used as anatomical landmarks to help with identification of the facial nerve at the level of brainstem. The point of origin of the facial nerve from the brainstem is 2 to $3 \mathrm{~mm}$ above the most rostral rootlet of the glossopharyngeal nerve. The foramen of Luschka, the sleevelike lateral recess of the fourth ventricle, is situated at the lateral margin of the pontomedullary sulcus, just behind the junction of the glossopharyngeal nerve with the brainstem, and immediately posteroinferior to the junction of the facial and vestibulocochlear nerves with the brainstem. The foramen itself is infrequently well visualized but tuft of the choroid plexus protruding out of the foramen of Luschka over the posterior surface of the glossopharyngeal and vagus nerves, just inferior to the junction of the facial and vestibulocochlear nerves with the brainstem can be well identified (Friedland \& Wackym, 1999, Rhoton, 2000a, Koval \& Krempaska, 2009). Flocculus, projects from the margin of the lateral recess and foramen of Luschka into the cerebellopontine angle, just posterior to facial and vestibulocochlear nerves.

Proper identification of the foramen of Luschka represent a crucial step in successful placement of the auditory brainstem neuroprosthesis to rehabilitate deafness in the cases of bilateral cochlear nerve loss. Choroid plexus, glossopharyngeal nerve and possibly stump of the eighth nerve represent key anatomical landmarks of the foramen of Luschka (Colleti et al. 2000, Skrivan et al. 2003, Brito Neto et al. 2005).

As stated earlier the facial and vestibulocochlear nerve are in close contact with AICA at the level of the brainstem. In most cases, the AICA passes below the nerves as it encircles the brainstem, but it also may pass above or between the nerves (Rhoton, 2000a, Rhoton, 2000c). Both nerves show relationship with the vein of the pontomedullary sulcus, the veins of the cerebellomedullary fissure, middle cerebellar peduncle, and cerebellopontine fissure veins on the side of the brainstem (Rhoton, 2000a, Rhoton 2000d).

As the seventh-eigth nerve complex runs from the brainstem forward and laterally to the internal auditory canal they usually display contact with the loop of AICA which reaches the porus or protrudes into the canal in almost half of the cases. During the cisternal course the facial nerve is anterior, cochlear portion is inferior and posterior and vestibular portion is superior and posterior. As the nerves approach the porus of the internal auditory canal facial and cochlear portion of the eigth cranial nerve are anterior, and vestibular portion is posterior and lateral. The position of the nerves is most constant in the lateral portion of the internal auditory canal, which is divided into a superior and an inferior portion by the transverse or falciform crest. The facial and the superior vestibular nerves are superior to the 
transverse crest. The facial nerve is anterior to the superior vestibular nerve and is separated from it at the lateral end of the meatus by the vertical crest or "Bill's bar". The cochlear and inferior vestibular nerves are located below the transverse crest with the cochlear nerve located anteriorly and inferior vestibular nerve posteriorly. Because vestibular schw annoma arise in the posteriorly placed vestibular nerves, they usually displace the facial nerve anteriorly and cochlear nerves inferiorly and anteriorly (Rhoton, 2000a, Magnan et al. 2002, Miyazaki et al. 2005).

The nervus intermedius is usually joined to the ventral surface of the vestibulocochlear nerve a few millimetres adjacent to the brainstem, then has a free segment in the cisternal part as it courses to join the facial motor root.

Labyrinthine artery (or arteries) accompanying the nerves is usually a branch of premeatal segment of AICA, but it can arise from the meatal or postmeatal portion of AICA, basilar artery or posterior inferior cerebellar artery (Rhoton, 2000a, Rhoton 2000c). Injury of the internal auditory artery can hamper hearing preservation during vestibular schwannoma removal.

Looking on the posterior petrosal face we can identify the subarcuate fossa that is enetered by the subarcuate artery. It is located superolateral to the porus of internal auditory canal.

Other important structures are the endolymphatic duct and sac, situated inferolateral to the internal auditory canal. It should be preserved when elevating the dura and opening the canal if there is the possibility of preserving hearing.

The lower neurovascular complex is related to the posterior inferior cerebellar artery, and includes the medulla, inferior cerebellar peduncle, cerebellomedullary fissure, suboccipital surface of the cerebellum, and the glossopharyngeal, vagus, spinal accessory, and hypoglossal nerves (Fig.1) (Rhoton, 2000a, Cappabianca et al. 2002, Yuguang et al. 2005).

The posterior inferior cerebellar artery (PICA) arises from the vertebral artery at the medullary level, encircles the medulla, passing in relationship to the lower cranial and hypoglossal nerves to reach the surface of the inferior cerebellar peduncle, where it dips into the cerebellomedullary fissure and terminates by supplying the suboccipital surface of the cerebellum (Rhoton 2000c).

The glossopharyngeal nerve arises as one or rarely two rootlets from the upper medulla, posterior to the olive in the post-olivary sulcus, just caudal to the origin of the facial nerve. It courses ventral to the choroid plexus protruding from the foramen of Luschka on its way to the jugular foramen. The smaller ventral rootlet has been demonstrated to be motor and the larger dorsal rootlet to be sensory. The glossopharyngeal nerve enters the dural subcompartment of the jugular foramen called the glossopharyngeal meatus (Rhoton, 2000a).

The vagus nerve arises below the glossopharyngeal nerve in the post-olivary sulcus as tightly packed rootlets posterior to the superior third of the olive. The most rostral vagal fibers arise adjacent to the glossopharyngeal rootlets. The vagus nerve is composed of multiple combinations of large and small rootlets that pass ventral to the choroid plexus protruding from the foramen of Luschka on its way to the jugular foramen. The vagal rootlets enter the dural subcompartment of the jugular foramen called the vagal meatus. It is inferior to the glossopharyngeal meatus from which it is separated by a dural septum. The vagus nerve is joined by the accessory nerve as it enters the dura (Rhoton, 2000a).

The accessory nerve arises as a widely separated series of rootlets that originated from the medulla at the level of the lower two-thirds of the olive and from the upper cervical cord. 
The cranial rootlets arise as a line of rootlets just caudal to the vagal fibers in the post-olivary sulcus. These are more properly regarded as inferior vagal rootlets, since they arise from vagal nuclei. It may be difficult to separate the lower vagal fibers from the upper accessory rootlets because the vagal and cranial accessory fibers usually enter the vagal meatus as a single bundle. The upper rootlets of the spinal portion of the accessory nerve originate several millimeters caudal to the lowest cranial accessory fibers and either course to join the cranial accessory bundle or enter the lower border of the vagal meatus separate from the cranial accessory rootlets. The spinal accessory fibers pass superolateral from their origin to reach the jugular foramen. Although the cranial and spinal portion of the accessory nerve most frequently enter the vagal meatus together, they may infrequently be separated by a dural septum (Rhoton, 2000a).

The rootlets of the hypoglossal nerve arise from the medulla along the anterior margin of the lower two-thirds of the olive in the preolivary sulcus. The rootlets course anterolateral through the subarachnoid space and pass behind the vertebral artery to reach the hypoglossal canal. Before entering the canal, the rootlets collect into two bundles, and in some cases, the canal is even divided by a bony septum that separates the two bundles (Rhoton, 2000a).

\section{Technique of minimally invasive endoscopic and endoscopy-assisted microsurgery of vestibular schwannoma}

In its basic aspects the surgery proceeds in a similar fashion as an neurotological procedure.

General endotracheal anesthesia is administered, profound and balanced with paralysis avoided. Before durotomy, both controlled hypotension and assisted hyperventilation to obtain a pCO2 of about $25 \mathrm{~mm} \mathrm{Hg}$ are crucial to lower the intracranial pressure and to help spontaneous cerebellar retraction. Bolus of corticoids at the same moment can be beneficial. Mannitol infusions and lumbar drainage are not needed (Miyazaki et al. 2005, Goksu et al. 2006, Betka et al. 2010). If experience shows that the surgery will take more than 3 hours a Foley catheter is placed. A second generation cephalosporin is used for perioperative prophylaxis.

The patient is placed in supine position with the head rotated aw ay from the ipsilateral ear. Patient positioning is crucial, making sure that the shoulder does not restrict access to the surgical field and proper manipulation with instruments. Fixation of the skull is usually not necessary, fastening of the contralateral forehead with a gel sheet is adequate. Another option is to secure the head in a Mayfield 3-pin head clamp. The table is positioned so that the head is elevated above the level of heart.

For the approach the area to be shaved, only 2 to $3 \mathrm{~cm}$ behind the ear is sufficient. The landmarks for skin incison are Frankfurt line joining the outer canthus to the superior part of the external auditory meatus, and a line along the posterior margin on the mastoid. Placement of a minicraniotomy can be marked as a $2 \mathrm{~cm}$ circle below and behind from the point where the two lines cross. The incision is outlined as an anterior concave line of 3 to $6 \mathrm{~cm}$ in length arching from the tip of the mastoid at a position one finger's width back of the oblique line by passing the backside of the keyhole (Fig.2). Placement of the incision is infiltrated with 1: 200000 Epinephrine. The skin flap is elevated with sharp dissection of the temporalis fascia and the pericranium ending at the level of the external auditory canal. Using the cautery knife and raspatory nuchal 
muscles are detached from the mastoid and occipital bone backwards and a self retaining retractor is placed in position.
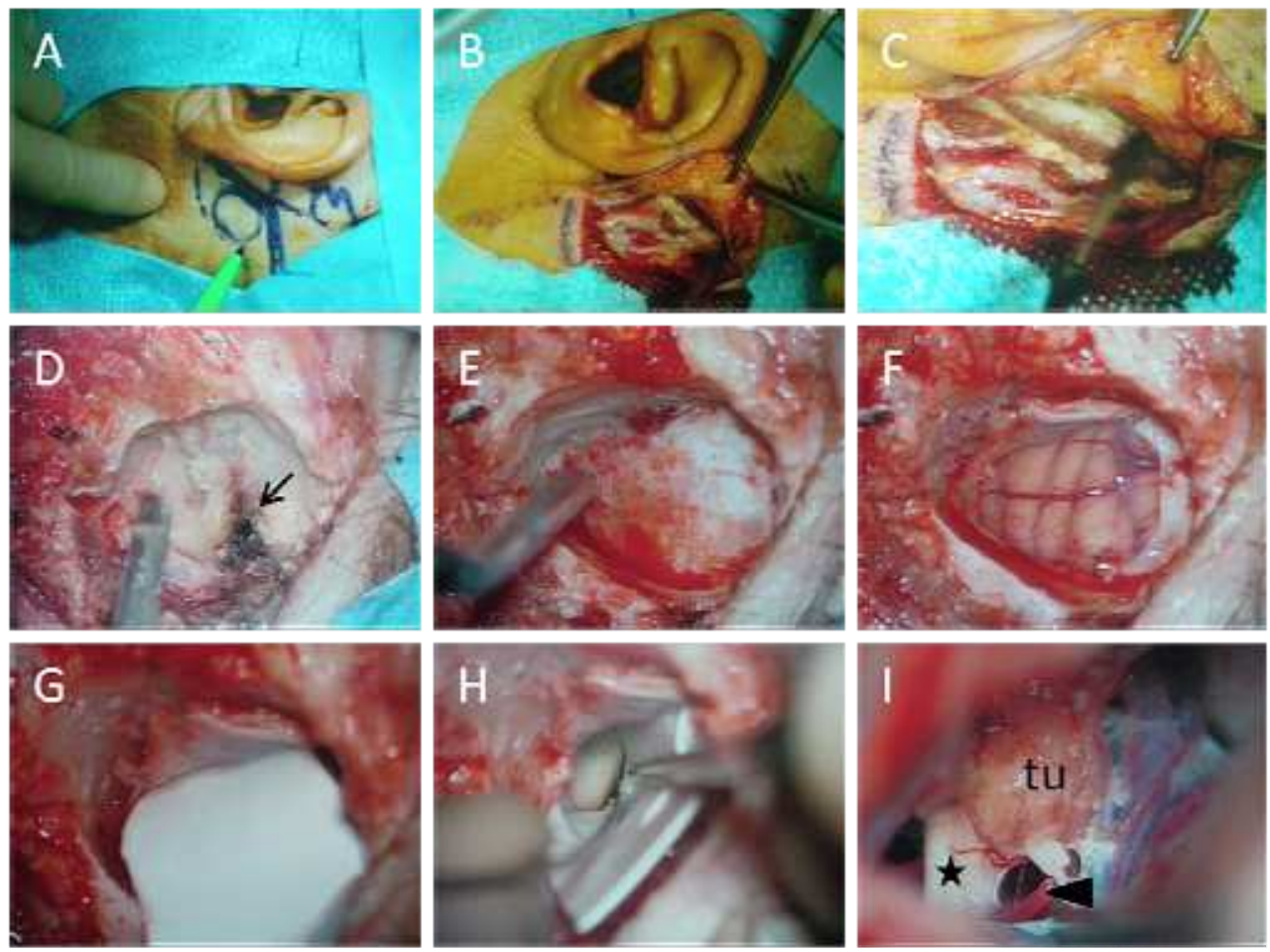

Fig. 2. Surgical steps of the minimally invasive retrosigmoid approach for vestibular schwannoma (left side). A: landmarks for skin incison (Frankfurt line and a line along the posterior margin on the mastoid) and place of minicraniotomy (circle) are outlined, B: elevation of the skin flap, C: detachment of the muscles, D: drilling is centered on the emissary vein (arrow), E: minicraniotomy is finished, it is centered on the confluence of sigmoid and transverse sinuses, F: anteriorly based dural flap is elevated and fixated with the suture, $\mathrm{G}$ and $\mathrm{H}$ : sheet of artificial dura is placed over the cerebellum, the cisterna is opened and cerebrospinal fluid is let to escape and the surgeon waits for the spontaneous cerebellar retraction to occur, $\mathrm{H}$ : once adequate cerebellar relaxation has been achieved no brain retractors are needed and dissection of tumor (tu) can proceed (asterisk denotes the seven-eight nerve bundle, arrowhead points on anterior inferior cerebellar artery).

Once adequate exposure of bone is achieved the keyhole craniotomy is performed (Magnan et al. 2002, Miyazaki et al. 2005). Using the cutting burr the drilling starts with the mastoid emissary vein in the centre as the landmark. Asterion represents another anatomic landmark for craniotomy placement as its helps to localize the confluence of sigmoid and transverse sinuses (Rhoton, 2000a, Rhoton, 2000b, Kabil \& Shahinian, 2006). All the bone dust is collected to prepare a pate that is solidified with fibrin glue at the end of surgery and used for craniotomy closure. In order to prevent cerebrospinal fluid leakage, all opened mastoid 
air cells are obliterated with the bone wax. If not used from the beginning it is suggested to use the operating microscope when the dura and posterior margin of sigmoid sinus is approached. It is even safer to use the diamante at this stage of drilling.
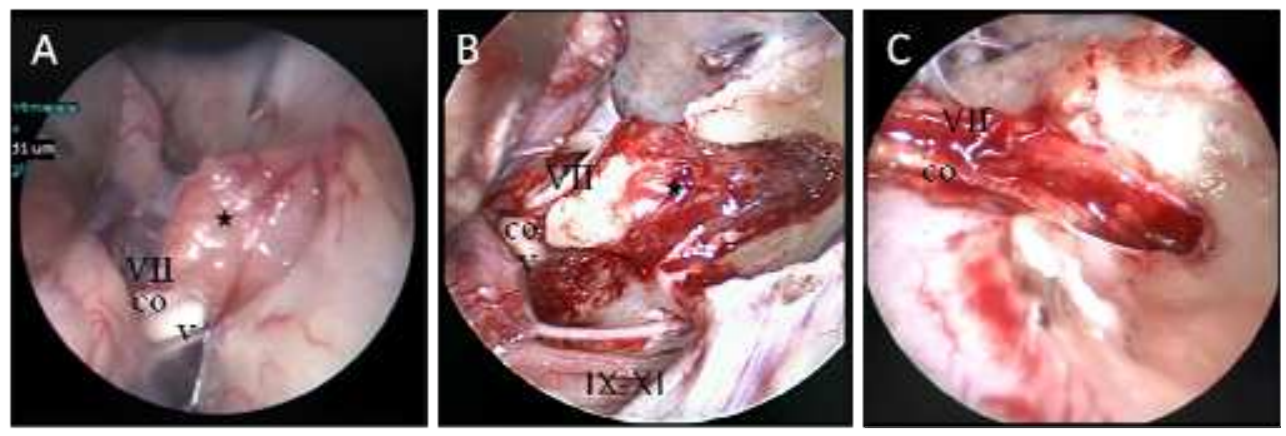

Fig. 3. Minimally invasive endoscopy-assisted removal of small (grade II) vestibular schwannoma (right side). A: anatomic mapping after opening the cisterna (VII: facial nerve, $\mathrm{v}$ : vestibular nerves, labyrinthine artery is in between the facial and vestibular nerves), B: internal auditory canal is opened and vestibular nerves sectioned and tumor (asterisk) is exposed, C: control of radicality of resection and integrity of facial and cochlear (co) nerves.
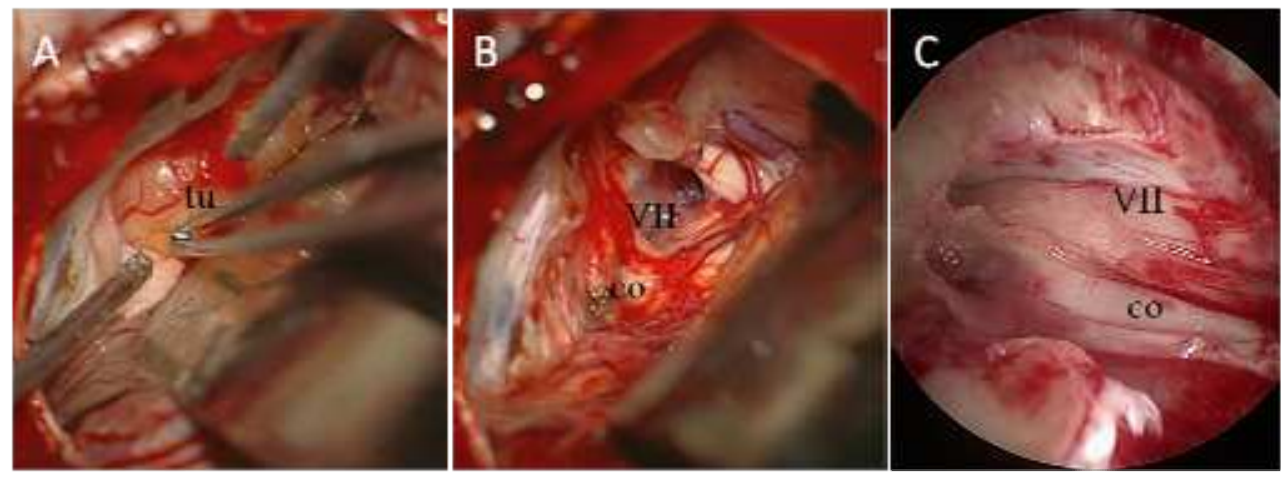

Fig. 4. Minimally invasive endoscopy-assisted removal of large (grade IV) vestibular schwannoma (left side) with preservation of facial and cochlear nerve including preoperatively useful hearing. A: anatomic mapping after opening the cistern, B: cisternal portion of tumor was removed with preservation of cochlear (co) and facial nerve (VII), C: $\mathrm{C}$ : control of radicality of resection and integrity of facial and cochlear (co) nerves.

After adequate exposure of the posterior fossa and hemostasis the dura can be incised. An anterior based U-shaped flap is appropriate as its fixation with stay suture helps to retract the sigmoid sinus to gain better access to the cerebellopontine angle. While suctioning of the cerebrospinal fluid, wait for spontaneous cerebellar retraction. Fine neurosurgical cotton $1.5 \mathrm{~cm}$ in width and $5 \mathrm{~cm}$ in length is placed over the cerebellum to protect it from injury. Cerebellum can be gently pressed by the mid portion of the suction that is gently advanced into the safe corridor between the hemisphere and posterior aspect of the 
petrous bone until the cerebellopontine cistern is opened at the level of lower cranial nerves. Once adequate cerebellar relaxation has been achieved it is usually not necessary to insert any brain retractor. The endoscopes used are mainly $0^{\circ}$ and $30^{\circ}$ angled rigid endoscopes of standard 2.7 and $4 \mathrm{~mm}$ in diameter and 6,11 and $14 \mathrm{~cm}$ in length according to the situation. If needed $45^{\circ}$ and $70^{\circ}$ angled rigid endoscopes are used. An irrigation sheath attached to the endoscope clears blood and debris from the lens, eliminating the time consuming and unsafe practice of removing and reinserting the endoscope. A pneumatic holding arm is preferred to secure the endoscope in position, allowing bimanual surgical dissection. Other option is freehand endoscopic technique with an endoscope being moved and held freehand by a second surgeon, with the first surgeon using two other instruments inside the surgical field.

The endoscope and the optical fiber cable used are completely sterilized by autoclaving. By covering the camera cable and the camera adaptor with a sterilized polyethylene cover, endoscopes can be easily exchanged under clean handling conditions. To maintain asepsis, the endoscopic examination is followed on a monitor.
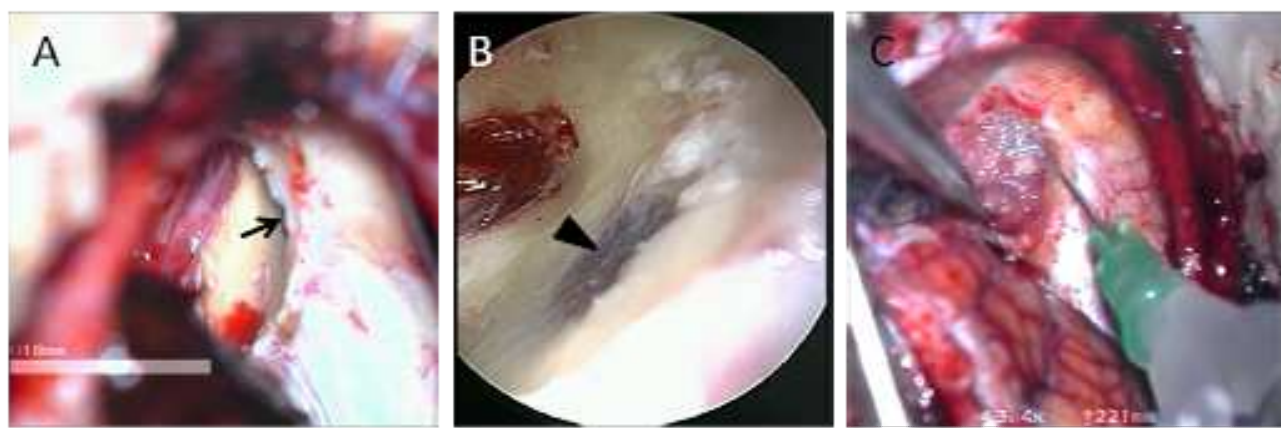

Fig. 5. Endoscopic identification of opened petrous bone air cells. A: with surgical microscope opened air cells might be not visualized with risk for cerebrospinal fluid leakage (position identified by arrow), B: endoscopic view with identification (arrowhead) of opened air cells after drilling of posterior meatal wall, C: sealing of the opened air cells with piece of muscle and tissue glue.

Upon entering the cerebellopontine angle a preliminary survey of the actual neurovascular anatomy including the trigeminal, facial, and lower cranial nerves, as well as the vascular structures is performed (Fig.3 and 4). Neuromonitoring of the facial nerve and hearing is a standard during vestibular schwannoma surgery. Function of the facial nerve stimulator can be checked with stimulation of the accessory nerve rootlets.

Once all the critical structures are identified tumor dissection can take place. The dura overlying the petrous bone posterior to internal auditory canal is cauterized and incised and a diamond bur is used to open the IAC, following the tumor extent laterally within the canal.

No matter whether microsurgical or endoscopic technique is used the basic surgical concept is always to debulk tumor in order to relieve the pressure on the surrounding neurovascular 
structures. Microdissecting instruments as well as the cavitron ultrasonic aspirator (CUSA) can be used to accomplish this step. Having completed debulking it is easier to appreciate the full anatomical course of the cranial nerves and vessels and to protect them from potential damage. During dissection the most adherent points between the tumor and nerves are recognized and addressed last.
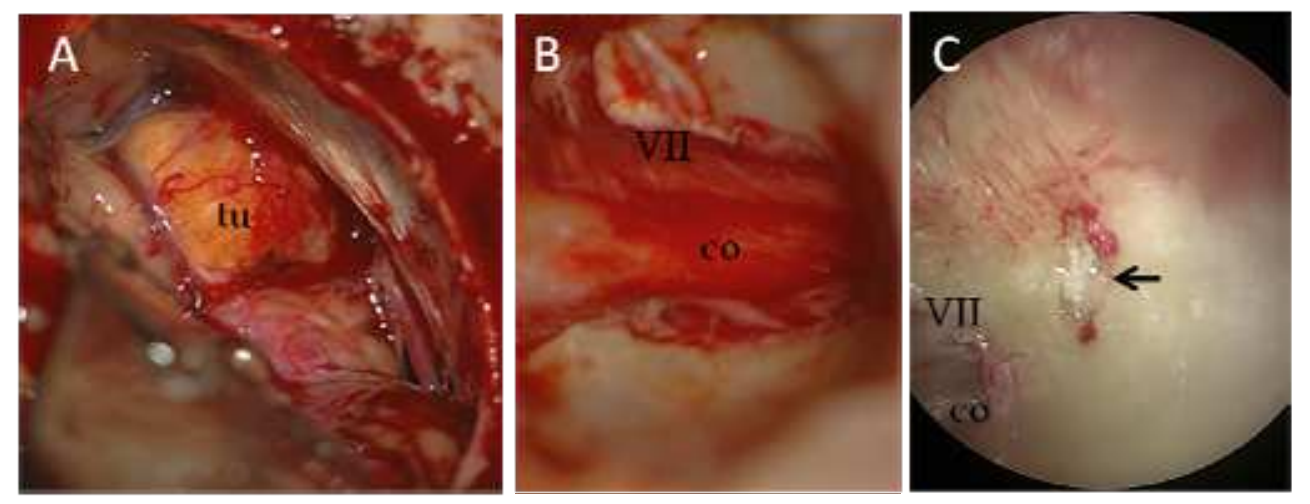

Fig. 6. Minimally invasive endoscopy-assisted removal of large (grade IV) vestibular schwannoma (right side) with preservation of facial and cochlear nerve but "unexplainable" loss of evoked auditory brainstem response during the internal auditory canal opening. A: view of the tumor (tu) after opening the cistern, B:endoscopic control of radicality of resection and integrity of facial (VII) and cochlear (co) nerves, C: loss of hearing was explained with identification of the opened posterior semicircular canal (arrow).

If endoscopic technique is preferred the dissection in the region of the cerebellopontine angle is guided by a $0^{\circ}$ endoscope in much the same manner as the microsurgical procedure. Tumor dissection within the internal auditory canal is guided preferentially by the $30^{\circ}$ angled endoscope, allowing complete visualization of the lateral extent of the tumor as it is separated from the facial and cochlear nerves. The endoscopes are inserted in the upper part of approach, perpendicular to the sigmoid sinus, or in the angle between the petrous bone and tentorium, while the surgical instruments are inserted below it, along the cerebellar surface. Such position permits both inspection of the relationship between the tumor and critical neurovascular structures, and continuous control of surgical manoeuvres of the instruments, which constantly remain under direct endoscopic view.

Once tumor dissection is completed endoscopic inspection of fundus of the internal auditory canal for residual tumor, integrity of cochlear and facial nerves and meticulous inspection of drilled-out portion of the petrous bone for open air cells that need sealing is performed (Fig.3, 4, 5, 6 and 7). The facial nerve is once again stimulated to confirm its function. Small pieces of fat or muscle together with fibrin glue are used to seal the opened internal auditory canal and petrous bone air cells. Cisterns are repeatedly washed. The dura is reapproximated and sutured to provide a watertight closure.

Bony pate is used to replace the drilled bone at the craniotomy site. Soft tissues of the scalp are closed in anatomical layers without the use of any drains. Following the surgery the 
patients are typically transferred to intensive care unit for overnight monitoring. Early vestibular rehabilitation is supported postoperatively.
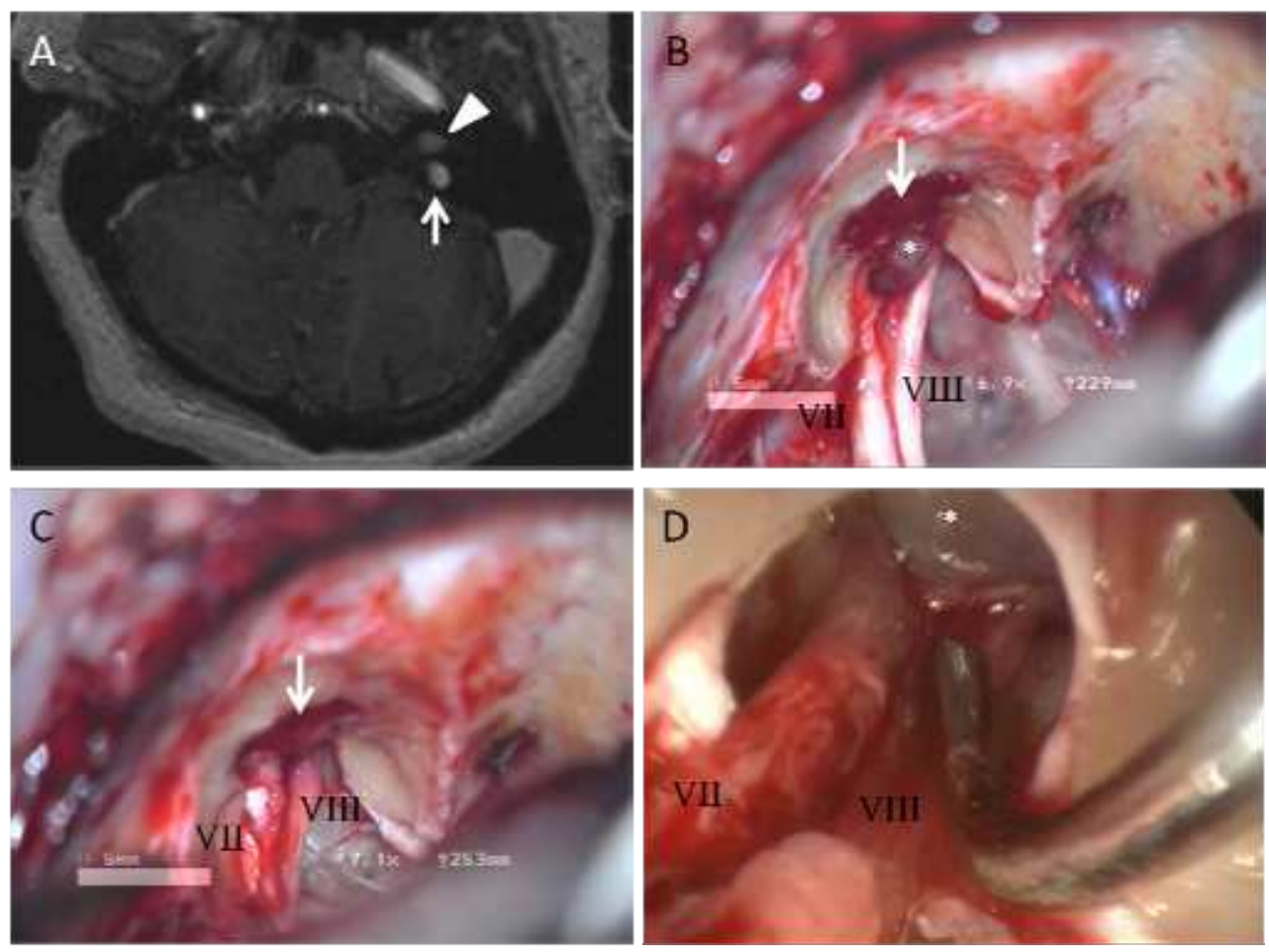

Fig. 7. Minimally invasive endoscopy-assisted removal of intrameatal (grade I) vestibular schw annoma (left side) in case of high jugular bulb. A: MRI showing the high jugular bulb (arrow) being positioned posterior to the internal auditory canal and tumor (arrowhead), B: after drilling the posterior meatal wall high jugular bulb blocks the approach to the medial portion of the tumor, facial (VII) and vestibulocochlear nerve (VIII) can be seen, C: jugular bulb was compressed and major part of the tumor was removed, D: endoscope is used to control tumor removal in the region of fundus of the internal auditory canal.

\section{Conclusions}

The recent technological advances provided high-quality endoscopes of small diameters and varying lengths and angles, irrigation sheaths for cleaning the lenses inside the operative field, endoscope holders that allow the surgeon to continue using their bimanual microsurgical skills and sophisticated instruments suitable for endoscopic microsurgery. These improvements permit us to use the endoscope, with its wide panoramic, multiangled, and close-up view of the anatomic structures, to ideally express its best properties in deepseated and narrow space-located lesions of the skull base. 
The introduction of endoscopic technique into the repertoire of the surgical methods of treatment of the cerebellopontine angle pathologies has proved to be useful. Although only limited surgical series concerning the employment of the endoscopic techniques for the removal of vestibular schwannomas have been reported recently, it seems clear that the endoscopes offer some advantages over the conventional microsurgical technique either in reducing the invasiveness or in allowing safer and more radical tumor removal, thus helping to lower the complication rate and improving the results. Nevertheless, good equipment and special training are absolutely necessary for attainment of optimal results.

\section{Acknowledgements}

This work was supported by grants of the Internal Grant Agency of the Ministry of Health of the Czech Republic NS/ 9909-4, NT/ 12459-5, NT/ 11543-6 and Charles University project for support of Specific University Research No. 262510. Authors are grateful to Daniel Kameny M.D. for reading the manuscript.

\section{References}

Badr-El-Dine M, El-Garem HF, Talaat AM, Magnan J (2002). Endoscopically assisted minimally invasive microvascular decompression of hemifacial spasm. Otol Neurotol 23:122-128.

Betka J, Zverina E, Lisy J, Chovanec M, Kluh J, Kraus J (2008). Vestibular schwannoma. Otorinolaryngol Phoniatr (Prague) 57:221-225.

Betka J, Zverina E, Chovanec M, Kluh J, Lukes P, Kraus J, Lisy J(2009). Minimally invasive endoscopic and endoscopy-assisted microsurgery of vestibular schwannoma. Endoskopie 18:67-71.

Bremond G, Garcin M, Magnan J, Bonnaud G (1974). L’abord a minima de l'espace pontocerebelleux. Cah ORL 19:443-460.

Bremond G, Garcin M (1975). Microsurgical approach to the cerebellopontine angle. J Laryngol Otol 89:237-248.

Brito Neto RV, Bento RF, Yasuda A, Ribas GC, Rodrigues AJ Jr (2005). Anatomical references in auditory brainstem implant surgery. Braz J Otorhinolaryngol 71:282286.

Cakrt O, Chovanec M, Funda T, Kalitova P, Betka J, Zverina E, Kolar P, Jerabek J (2010). Exercise with visual feedback improves postural stability after vestibular schwannoma surgery. Eur Arch Otorhinolaryngol 267:1355-1360.

Cappabianca P, Cavallo LM, Esposito F, de Divitiis E, Tschabitscher M (2002). Endoscopic examination of the cerebellar pontine angle. Clin Neurol Neurosurg 104:387-391.

Chen MJ, Zhang WJ, Yang C, Wu YQ, Zhang ZY, Wang Y (2008). Endoscopic neurovascular perspective in microvascular decompression of trigeminal neuralgia. $J$ Craniomaxillofac Surg 36:456-461.

Cheng WY, Chao SC, Shen CC (2008). Endoscopic microvascular decompression of the hemifacial spasm. Surg Neurol 70 Suppl 1:40-46. 
Cheng S, Naidoo Y, da Cruz M, Dexter M (2009). Quality of life in postoperative vestibular schwannoma patients. Laryngoscope 119:2252-2257.

Clemis $\mathbb{D}$, Ballad WJ, Baggot PJ, Lyon ST (1986). Relative frequency of inferior vestibular schwannoma. Arch Otolaryngol Head Neck Surg 112:190-194.

Colletti V, Fiorino FG, Carner M, Giarbini N, Sacchetto L, Cumer G (2000). Advantages of the retrosigmoid approach in auditory brain stem implantation. Skull Base Surg 10:165-170.

Colletti V, Fiorino F (2005). Is the middle fossa approach the treatment of choice for intracanalicular vestibular schwannoma? Otolaryngol Head Neck Surg 132:459466.

de Divitiis O, Cavallo LM, Dal Fabbro M, Elefante A, Cappabianca P (2007). Freehand dynamic endoscopic resection of an epidermoid tumor of the cerebellopontine angle: technical case report. Neurosurgery 61:239-240.

Doyen E (1917). In: Surgical therapeutics and operative techniques, vol. 1., 599-602, Balliere, Tindall and Cox, London.

Ebner FH, Roser F, Shiozawa T, Ruetschlin S, Kirschniak A, Koerbel A, Tatagiba M (2009). Petrosal vein occlusion in cerebello-pontine angle tumour surgery: an anatomical study of alternative draining pathways. Eur JSurg Oncol 35:552-556.

Eby $\mathbb{B}$, Cha ST, Shahinian HK (2001). Fully endoscopic vascular decompression of the facial nerve for hemifacial spasm. Skull Base 11:189-197.

El-Garem HF, Badr-El-Dine M, Talaat AM, Magnan J (2002). Endoscopy as a tool in minimally invasive trigeminal neuralgia surgery. Otol Neurotol 23:132-135.

Friedland DR, Wackym PA (1999). Evaluation of surgical approaches to endoscopic auditory brainstem implantation. Laryngoscope 109:175-180.

Fries G, Perneczky A (1998). Endoscope-assisted brain surgery: Part 2-analysis of 380 procedures. Neurosurgery 42:226-232.

Fukushima T (1978). Endoscopy of Meckel's cave, cisterna magna and cerebellopontine angle. Technical note. JNeurosurg 48:302-306.

Gerganov VM, Giordano M, Herold C, Samii A, Samii M (2010). An electrophysiological study on the safety of the endoscope-assisted microsurgical removal of vestibular schwannomas. Eur JSurg Oncol 36:422-427.

Gerosa M, Mesiano N, Longhi M, De Simone A, Foroni R, Verlicchi A, Zanotti B, Nicolato A (2010). Gamma Knife surgery in vestibular schwannomas: impact on the anterior and posterior labyrinth. JNeurosurg 113 Suppl:128-135.

Goksu N, Bayazit Y, Kemaloglu Y (1999). Endoscopy of the posterior fossa and dissection of acoustic neuroma. JNeurosurg 91:776-780.

Goksu N, Yilmaz M, Bayramoglu I, Aydil U, Bayazit YA (2005). Evaluation of the results of endoscope-assisted acoustic neuroma surgery through posterior fossa approach. ORL JOtorhinolaryngol Relat Spec 67:87-91.

Goksu N, Bayazit YA, Bayramoglu I, Isik B, Yilmaz M, Kurtipek O, Uygur K (2006). Surgical exposure in retrosigmoid approach: do we need cerebellar retractors? Surg Neurol 65:631-634.

Griffith HB (1975). Technique of fontanelle and presutural ventriculoscopy and endoscopic ventricular surgery in infants. Childs Brain 1:359-363. 
Guevara N, Deveze A, Buza V, Laffont B, Magnan J (2008). Microvascular decompression of cochlear nerve for tinnitus incapacity: pre-surgical data, surgical analyses and long-term follow-up of 15 patients. Eur Arch Otorhinolaryngol 265:397-401.

Hori T, Okada Y, Maruyama T, Chernov M, Attia W (2006). Endoscope-controlled removal of intrameatal vestibular schwannomas. Minim Invasive Neurosurg 49:25-29.

Jarrahy R, Young J, Berci G, Shahinian HK (1999). Endoscopic skull base surgery II: a new animal model for surgery of the posterior fossa. J Invest Surg 12:335339.

Jarrahy R, Berci G, Shahinian HK (2000). Endoscope-assisted microvascular decompression of the trigeminal nerve. Otolaryngol Head Neck Surg 123:218-223.

Jarrahy R, Cha ST, Eby JB, Berci G, Shahinian HK (2002a). Fully endoscopic vascular decompression of the glossopharyngeal nerve. J Craniofac Surg. 13:9095.

Jarrahy R, Eby JB, Cha ST, Shahinian HK (2002b). Fully endoscopic vascular decompression of the trigeminal nerve. Minim Invasive Neurosurg 45:32-35.

Kabil MS, Eby $\mathbb{B}$, Shahinian HK (2005). Endoscopic vascular decompression versus microvascular decompression of the trigeminal nerve. Minim Invasive Neurosurg 48:207-212.

Kabil MS, Shahinian HK (2006). A series of 112 fully endoscopic resections of vestibular schw annomas. Minim Invasive Neurosurg 49:362-368.

Koval J, Molcan M, Bowdler AD, Sterkers JM (1993). Retrosigmoid transmeatal approach: an anatomic study of an approach used for preservation of hearing in acoustic neuroma surgery and vestibular neurotomy. Skull Base Surg 3:16-21.

Koval J, Krempaska S, Kaliarik L (2009). Minimal retrosigmoidal approach with applied endoscopy. Otorinolaryngol Phoniatr (Prague) 58:8-14.

Koval J, Krempaska S (2009). Anatomic logic of the foramen Luschka in neurootologic surgery. Otolaryngol Pol 63:398-402.

King WA, Wackym PA (1999). Endoscope assisted Surgery for acoustic neuromas Vestibular Schwannomas): early experience using the rigid hopkins telescope. Neurosurgery 44:1095-1102.

Koerbel A, Gharabaghi A, Safavi-Abbasi S, Samii A, Ebner FH, Samii M, Tatagiba M (2009). Venous complications following petrosal vein sectioning in surgery of petrous apex meningiomas. Eur JSurg Oncol 35:773-779.

Linskey ME (2000). Stereotactic radiosurgery versus stereotactic radiotherapy for patients with vestibular schwannoma: a Leksell Gamma Knife Society 2000 debate. J Neurosurg 93 Suppl 3:90-95.

Low WK (1999a). Middle cranial fossa approach to the internal auditory Meatus:A Chinese temporal bone study. ORL J Otorhinolaryngol Relat Spec 61:142145.

Low WK (1999b). Enhancing hearing preservation in endoscopic-assisted excision of acoustic neuroma via the retrosigmoid approach. J Laryngol Otol 113:973977. 
Magnan J, Chays A, Caces F, Lepetre C, Cohen JM, Belus JF, Bruzzo M (1993). Contribution of endoscopy of the cerebellopontine angle by retrosigmoid approach. Neuroma and neuro-vascular de compression. Ann Otolaryngol Chir Cervicofac 110:259-265.

Magnan J, Chays A, Lepetre C, Pencroffi E, Locatelli P (1994). Endoscopy of the cerebellopontine angle. Am JOtol 15:366-370.

Magnan J, Caces F, Locatelli P, Chays A (1997). Hemifacial spasm: endoscopic vascular decompression. Otolaryngol Head Neck Surg 117:308-314.

Magnan J, Barbieri M, Mora R, Murphy S, Meller R, Bruzzo M, Chays A (2002). Retrosigmoid approach for small and medium-sized acoustic neuromas. Otol Neurotol 23:141-145.

Martin HC, Sethi J, Lang D, Neil-Dwyer G, Lutman ME, Yardley L (2001). Patient-assessed outcomes after excision of acoustic neuroma: postoperative symptoms and quality of life. JNeurosurg 94:211-216.

McKennan K (1993). Endoscopy of the internal auditory canal during hearing conservation acoustic neuroma surgery. Am JOtol 14:259-262.

Mer SB, Derbyshire AJ, Brushenko A, Pontarelli DA (1967). Fiberoptic endotoscopes for examining the middle ear. Arch Otolaryngol 85: 387-393.

Miyazaki H, Deveze A, Magnan J (2005). Neuro-otologic surgery through minimally invasive retrosigmoid approach: endoscope assisted microvascular decompression, vestibular neurotomy, and tumor removal. Laryngoscope 15:1612-1617.

Myrseth E, Møller P, Wentzel-Larsen T, Goplen F, Lund-Johansen M (2006). Untreated vestibular schwannomas: vertigo is a powerful predictor for health-related quality of life. Neurosurgery 59:67-76.

Myrseth E, Pedersen PH, Møller P, Lund-Johansen M (2007). Treatment of vestibular schwannomas. Why, when and how? Acta Neurochir (Wien) 149:647-660.

Myrseth E, Møller P, Pedersen PH, Lund-Johansen M (2009). Vestibular schwannoma: surgery or gamma knife radiosurgery? A prospective, nonrandomized study. Neurosurgery 64:654-661.

O'Donoghue GM, O'Flynn P (1993). Endoscopic anatomy of the cerebellopontine angle. Am JOtol 14:122-125.

Oppel F (1978). Endoscopy of the cerebello-pontine angle: its diagnostic and therapeutic possibilities. In: Advances and Technical Standards in Neurosurgery, vol. 5, 269-275, Springer-Verlag, ISBN 0387814418, Berlin.

Oppel F (1981). Indications and operative technique for endoscopy of the cerebellopontine angle. In: The Cranial Nerves, Samii M, Jannetta P, 429-437, Springer-Verlag, ISBN 0387106200, Berlin.

Ozluoglu LN, Akbasak A (1996). Video endoscopy-assisted vestibular neurectomy: a new approach to the eighth cranial nerve. Skull Base Surg 6:215-219.

Perneczky A, Fries G (1998). Endoscope-assisted brain surgery: part 1--evolution, basic concept, and current technique. Neurosurgery 42:219-224.

Prott W (1974). Cisternoscopy endoscopy of the cerebello-pontine angle. Acta Neurochir 31:105-113. 
Putnam TJ(1942). The surgical treatment of infantile hydrocephalus. Surg Gynecol Obstet 76:171-182.

Rhoton AL Jr (2000a). The cerebellopontine angle and posterior fossa cranial nerves by the retrosigmoid approach. Neurosurgery 47 Suppl 3:93-129.

Rhoton AL Jr (2000b). The temporal bone and transtemporal approaches. Neurosurgery 47 Suppl 3: 211-265.

Rhoton AL Jr (2000c). The cerebellar arteries. Neurosurgery 47 Suppl 3: 29-68.

Rhoton AL Jr (2000d). The posterior fossa veins. Neurosurgery 47 Suppl 3:69-92.

Rosenberg SI, Silverstein H, Willcox TO, Gordon MA (1994). Endoscopy in otology and neurootology. Am JOtol 15:168-172.

Roser F, Tatagiba MS (2010). The first 50s: can we achieve acceptable results in vestibular schwannoma surgery from the beginning? Acta Neurochir (Wien) 152:1359-1365.

Ryzenman $\mathbb{M}$, Pensak ML, Tew $\mathbb{M}$ Jr (2005). Headache: a quality of life analysis in a cohort of 1,657 patients undergoing acoustic neuroma surgery, results from the acoustic neuroma association. Laryngoscope 115:703-711.

Sakamoto GT, Blevins N, Gibbs IC (2009). Cyberknife radiotherapy for vestibular schwannoma. Otolaryngol Clin North Am 42:665-675.

Saman Y, Bamiou DE, Gleeson M (2009). A contemporary review of balance dysfunction following vestibular schw annoma surgery. Laryngoscope 119:2085-93.

Samii M, Matthies C (1997). Management of 1000 vestibular schwannomas (acoustic neuromas): the facial nerve-preservation and restitution of function. Neurosurgery 40:684-694.

Sandooram D, Grunfeld EA, McKinney C, Gleeson MJ (2004). Quality of life following microsurgery, radiosurgery and conservative management for unilateral vestibular schwannoma. Clin Otolaryngol Allied Sci 29:621-627.

Schroeder HW, Oertel J, Gaab MR (2004). Endoscope-assisted microsurgical resection of epidermoid tumors of the cerebellopontine angle. J Neurosurg 101:227232.

Schroeder HW, Nehlsen M (2009). Value of high-definition imaging in neuroendoscopy. Neurosurg Rev 32:303-308.

Shahinian HK, Eby $\mathbb{B}$, Ocon M (2004). Fully endoscopic excision of vestibular schw annomas. Minim Invasive Neurosurg 47:329-332.

Skrivan J, Zverina E, Betka J, Svetlik M, Kluh J, Sollmann WP, Kraus J, Belsan T, Tichy T, Sedlak S, Topol M (2003). Use of the auditory brainstem neuroprosthesis in the Czech Republic. Cas Lek Cesk 142:29-33.

Skrivan J, Zverina E, Betka J, Kluh J, Kraus J (2004). Our surgical experience with large vestibular schw annomas. Otolaryngol Pol 58:69-72.

Springborg $\mathbb{B}$, Poulsgaard L, Thomsen J(2008). Nonvestibular schwannoma tumors in the cerebellopontine angle: a structured approach and management guidelines. Skull Base 18:217-227.

Stangerup SE, Tos M, Thomsen J, Caye-Thomasen P (2010). True incidence of vestibular schw annoma? Neurosurgery 67:1335-1340. 
Sughrue ME, Yang I, Aranda D, Kane AJ, Parsa AT (2010a). Hearing preservation rates after microsurgical resection of vestibular schw annoma. JClin Neurosci 17:11261129.

Sughrue ME, Yang I, Rutkowski MJ, Aranda D, Parsa AT (2010b). Preservation of facial nerve function after resection of vestibular schwannoma. Br J Neurosurg 24):666671.

Sughrue ME, Kane AJ, Kaur R, Barry JJ, Rutkowski MJ, Pitts LH, Cheung SW, Parsa AT (2011). A prospective study of hearing preservation in untreated vestibular schw annomas. JNeurosurg 114:381-385.

Tallan EM, Harner SG, Beatty CW, Scheithauer BW, Parisi dE (1993). Does the distribution of Schwann cells correlate with the observed occurrence of acoustic neuromas? Am J Otol 14:131-134.

Tatagiba M, Matthies C, Samii M (1996). Microendoscopy of the internal auditory canal in vestibular schwannoma surgery. Neurosurgery 38:737-740.

Valtonen HJ, Poe DS, Heilman CB, Tarlov EC (1997). Endoscopically assisted prevention of cerebrospinal fluid leak in suboccipital acoustic neuroma surgery. Am J Otol 18:381-85.

Wackym PA, King WA, Barker FG, Poe DS (1998). Endoscope-assisted vestibular neurectomy. Laryngoscope 108:1787-1793.

Wackym PA, King WA, Poe DS, Meyer GA, Ojemann RG, Barker FG, Walsh PR, Staecker H (1999). Adjunctive use of endoscopy during acoustic neuroma surgery. Laryngoscope 109:1193-1201.

Wackym PA, King WA, Meyer GA, Poe DS (2002). Endoscopy in neuro-otologic surgery. Otolaryngol Clin North Am 35:297-323.

Wackym PA (2005). Stereotactic radiosurgery, microsurgery, and expectant management of acoustic neuroma: basis for informed consent. Otolaryngol Clin North Am 38:653670.

Wackym PA, Hannley MT, Runge-Samuelson CL, Jensen J, Zhu YR (2008). Gamma Knife surgery of vestibular schwannomas: longitudinal changes in vestibular function and measurement of the Dizziness Handicap Inventory. J Neurosurg 109 Suppl:137-143.

Wanibuchi M, Fukushima T, McElveen JT Jr, Friedman AH (2009). Hearing preservation in surgery for large vestibular schwannomas. JNeurosurg 111:845-854.

Yamakami I, Uchino Y, Kobayashi E, Yamaura A (2003). Conservative management, gamma-knife radiosurgery, and microsurgery for acoustic neurinomas: a systematic review of outcome and risk of three therapeutic options. Neurol Res 25:682-690.

Yang I, Sughrue ME, Han SJ, Aranda D, Pitts LH, Cheung SW, Parsa AT (2010). A comprehensive analysis of hearing preservation after radiosurgery for vestibular schwannoma. JNeurosurg 112:851-859.

Yuguang L, Chengyuan W, Meng L, Shugan Z, Wandong S, Gang L, Xingang L (2005). Neuroendoscopic anatomy and surgery of the cerebellopontine angle. J Clin Neurosci 12:256-260. 
Zverina E (2010). Acoustic neuroma--vestibular schwannoma--personal experience of up-todate management. Cas Lek Cesk 149:269-276. 


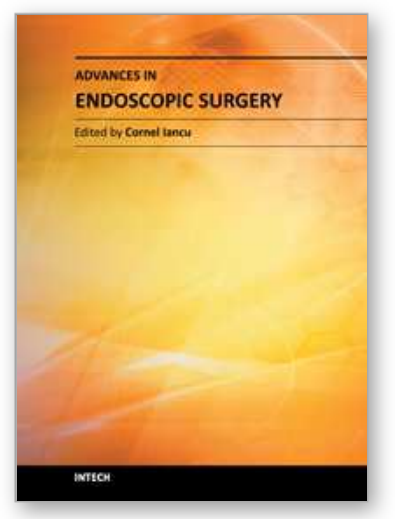

\author{
Advances in Endoscopic Surgery \\ Edited by Prof. Cornel lancu
}

ISBN 978-953-307-717-8

Hard cover, 444 pages

Publisher InTech

Published online 25, November, 2011

Published in print edition November, 2011

Surgeons from various domains have become fascinated by endoscopy with its very low complications rates, high diagnostic yields and the possibility to perform a large variety of therapeutic procedures. Therefore during the last 30 years, the number and diversity of surgical endoscopic procedures has advanced with many new methods for both diagnoses and treatment, and these achievements are presented in this book. Contributing to the development of endoscopic surgery from all over the world, this is a modern, educational, and engrossing publication precisely presenting the most recent development in the field. New technologies are described in detail and all aspects of both standard and advanced endoscopic maneuvers applied in gastroenterology, urogynecology, otorhinolaryngology, pediatrics and neurology are presented. The intended audience for this book includes surgeons from various specialities, radiologists, internists, and subspecialists.

\title{
How to reference
}

In order to correctly reference this scholarly work, feel free to copy and paste the following:

Betka Jan, Chovanec Martin, Zverina Eduard, Profant Oliver, Lukes Petr, Skrivan Jiri, Kluh Jan and Fik Zdenek (2011). Minimally Invasive Endoscopic and Endoscopy-Assisted Microsurgery of Vestibular Schwannoma, Advances in Endoscopic Surgery, Prof. Cornel lancu (Ed.), ISBN: 978-953-307-717-8, InTech, Available from: http://www.intechopen.com/books/advances-in-endoscopic-surgery/minimally-invasive-endoscopic-andendoscopy-assisted-microsurgery-of-vestibular-schwannoma

\section{INTECH}

open science | open minds

\author{
InTech Europe \\ University Campus STeP Ri \\ Slavka Krautzeka 83/A \\ 51000 Rijeka, Croatia \\ Phone: +385 (51) 770447 \\ Fax: +385 (51) 686166 \\ www.intechopen.com
}

\author{
InTech China \\ Unit 405, Office Block, Hotel Equatorial Shanghai \\ No.65, Yan An Road (West), Shanghai, 200040, China \\ 中国上海市延安西路65号上海国际贵都大饭店办公楼 405 单元 \\ Phone: +86-21-62489820 \\ Fax: $+86-21-62489821$
}


(C) 2011 The Author(s). Licensee IntechOpen. This is an open access article distributed under the terms of the Creative Commons Attribution 3.0 License, which permits unrestricted use, distribution, and reproduction in any medium, provided the original work is properly cited. 